Submission ID: 43771

\title{
Results of Geochemical Research of Asphaltites of the Ivanovo Deposit of
} the Orenburg Region

M.V. Zaharchenko* (Gubkin Russian State University of Oil and Gas), V.Y. Kerimov (Gubkin Russian State University of Oil and Gas), R.N. Mustaev (Gubkin Russian State University of Oil and Gas), M.M. Lyushin (Gubkin Russian State University of Oil and Gas), I.M. Salihova (Gubkin Russian State University of Oil and Gas)

\section{SUMMARY}

Based on the study, it was revealed that the initial material for the formation of asphaltite of the Ivanovo deposit was oil generated at the stages of catagenesis corresponding to the beginning of the main phase of oil formation. Sedimentation and diagenesis took place in coastal-marine conditions in a reducing environment in the zone of hydrogen sulfide contamination. 
Результаты геохимческих исследований асфальтитов Ивановского месторождения Оренбургской области

М.В. Захарченко* (РГУ нефти и газа (НИУ) имени И.М. Губкина), В.Ю. Керимов (РГУ нефти и газа (НИУ) имени И.М. Губкина), Р.Н. Мустаев (РГУ нефти и газа (НИУ) имени И.М. Губкина), М.М. Люшин (РГУ нефти и газа (НИУ) имени И.М. Губкина), И.М. Салихова (РГУ нефти и газа (НИУ) имени И.М. Губкина).

Исследования проведены при финансовой поддержке Минобрнауки России в рамках Задания №10.6569.2017/БЧ на выполнение научно-исследовательской работы (базовая часть государственного задания в сфере научной деятельности).

Ивановское месторождение асфальтитов расположенно в Оренбургской области, на юговосточном склоне Русской платформы в пределах Малокинельской системы прогибов. В разрезе Ивановской площади присутствуют залежи трех видов каустобиолитов: нефти в кунгурском ярусе, газа - в калиновской свите казанского яруса и асфальтита - в гидрохимической свите казанского яруса. Мощность залежи асфальтитов изменчива в крест простирания сводовой части и достаточно выдержана по простиранию, изменяясь в пределах расстояний между скважинами в 300-700 м от 7,0 до 2,5 м или от 4,5 до 0,5 м. Асфальтиты Ивановского месторождения представлены гильсонитом. Химический состав гильсонита представляет собой сложное сочетание элементов, которые включают серу, углерод, кислород, водород, азот и небольшие количества других элементов. Этот уникальный минерал используется в более чем 160 продуктах - нефтяных буровых растворах и цементах, асфальтовых модификаторах, печатных красках и чернилах тёмных тонов, добавках для формовочных смесей и прочих химических продуктах. Асфальтиты Ивановского месторождения залегают на глубине 400 м, вмещающей породой является галит (каменная соль). Средняя мощность линзообразной залежи составляет 4-5 метров. Асфальтит Ивановского месторождения представляет собой 99,9\% чистый уникальный углеводородный полимер.

Для характеристики условий формирования асфальтита применяются его органические геохимические параметры, в том числе, полученные на основе программированных пиролитических методов Rock-Eval [14]. Были проведены пиролитические исследования 5-ти образцов асфальтита скважины Ивановское методом Rock-Eval - 6 первоначально по программе bulk rock (Рис. 1 и 2). Видно, что пиролитический параметр $\mathrm{S}_{1}$ варьирует от 30,97 до 32,27 мг УВ/г породы, $\mathrm{S}_{2}-437,94$ - 486,4 мг УВ/г породы.

Низкий показатель параметра $\mathrm{S}_{1}$ указывает на небольшое содержание в образцах жидких углеводородов, что можно объяснить гипергенными изменениями исходной нефти, в частности, испарением легких ее фракций. Практическое отсутствие кислородного индекса ОI свидетельствует о низком уровне окисления. Близость полученных органических геохимических параметров проб свидетельствует об однородности компонентного состава асфальтита. Усредненное значение параметра Tmax $=437^{\circ} \mathrm{C}$ характеризует ОВ асфальтита как находящееся на ранней стадии термической зрелости, на которой углеводороды попадают во вмещающую породу, обладающей низкой пористостью, а потому слабой проницаемостью, и находятся в этот период вблизи от начала нефтяного окна. Сложная химическая природа асфальто-смолистых соединений битумов накладывает отпечаток на результаты пирогенных анализов, что проявляется в том, что в пирограммах изучаемых образцов наблюдается наложение пиков в интервалах выхода как $\mathrm{S}_{1}$, так и $\mathrm{S}_{2}$, что делает невозможным применение стандартных интерпретаций нефтематеринских пород [1]. В этой связи, были проведены дополнительные анализы по программе reservoir, позволяющей детализировать содержание асфальто-смолистых компонентов в образцах. Поскольку программа начинается при более низких температурах и имеет другой температурный режим, то позволяет дифференцировать легкие УВ, тяжелые УВ и смолы, а также асфальтены и тяжелую часть смол. 

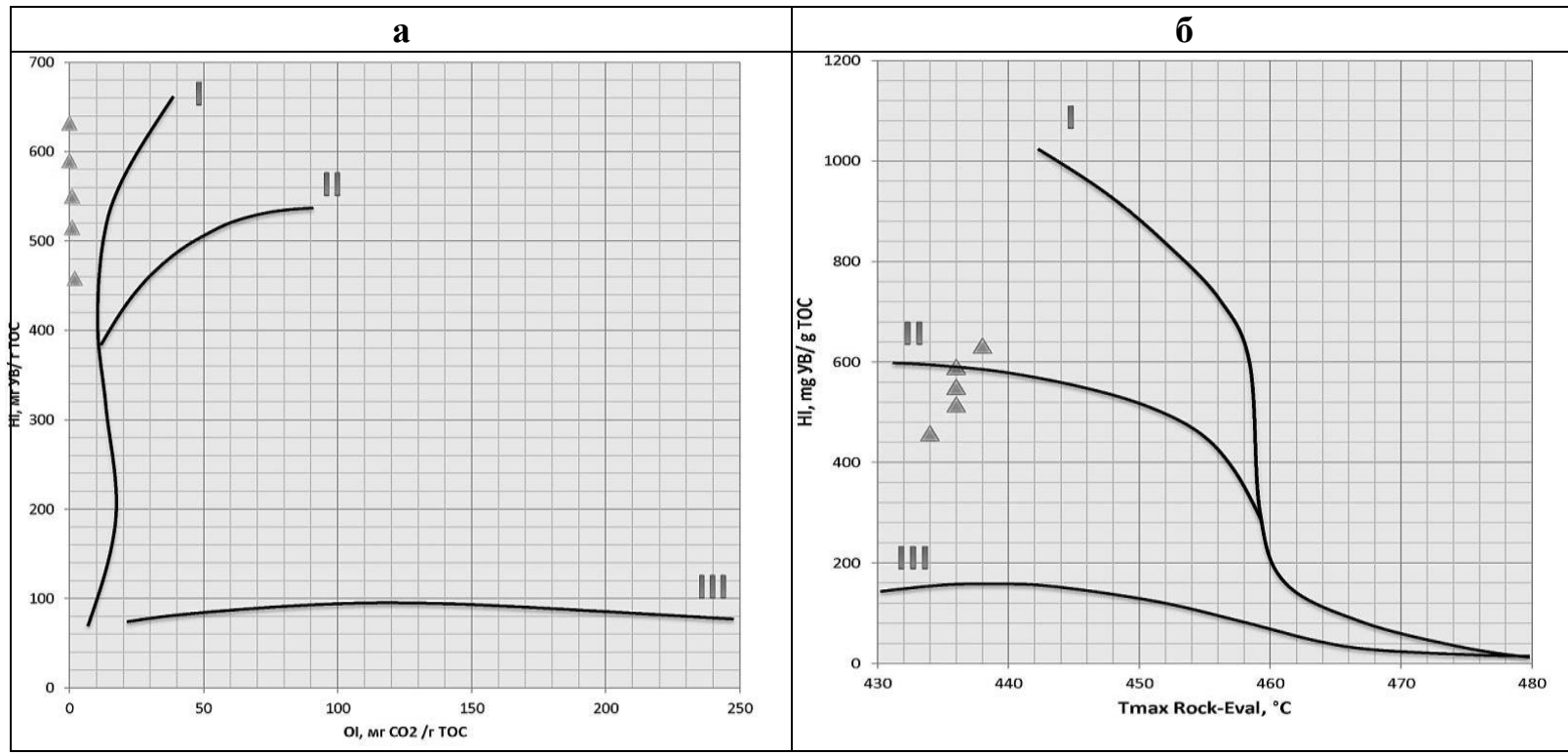

Рисунок 1 Модифицированные диаграммы Ван-Кревелена - зависимость водородного индекса HI от кислородного индекса ОI (а) и зависимости водородного индекса НI от максимальной температуры пиролиза Ттах (б).

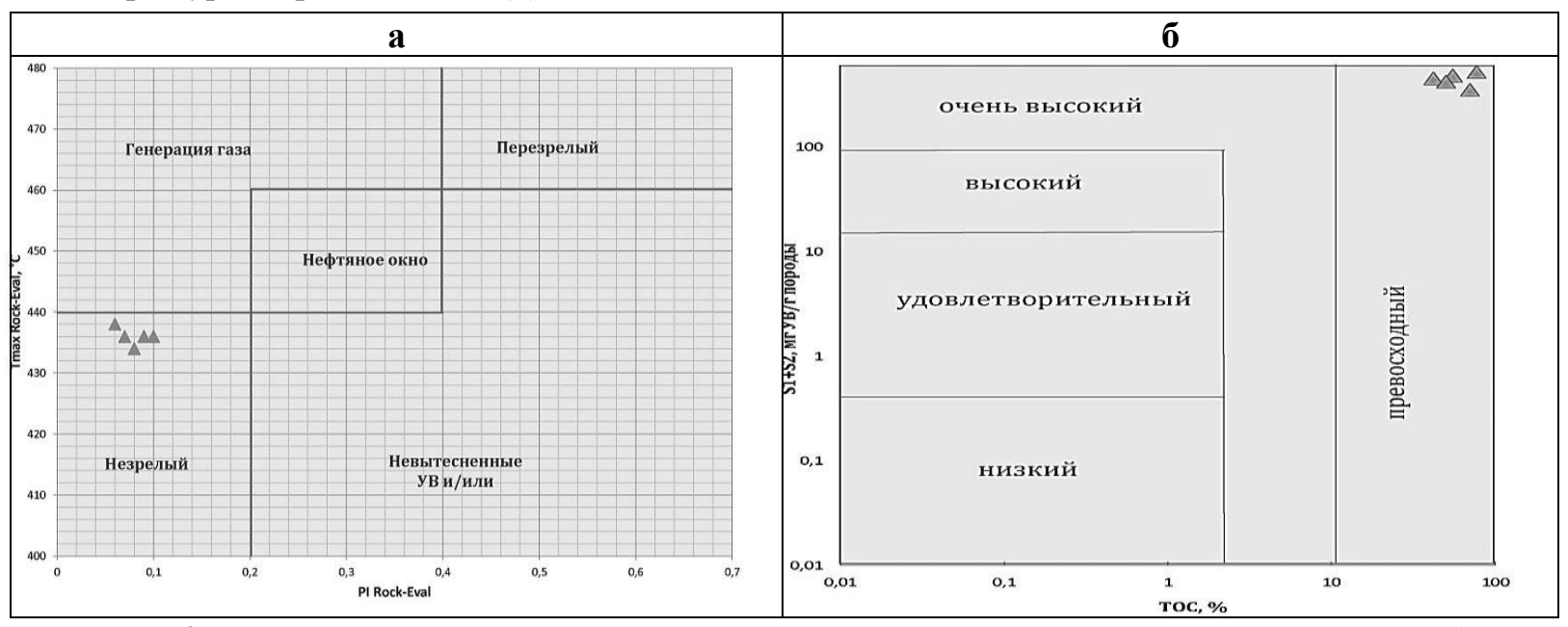

Рисунок 2 Диаграммы соотномений максимальной температуры пиролиза Ттах и индекса продуктивности PI (a), а также полного потенциала $\left(S_{1}+S_{2}\right)$ и общего органического углерода ТОС (б).

В этой связи, были проведены дополнительные анализы по программе reservoir, позволяющей детализировать содержание асфальто-смолистых компонентов в образцах. Поскольку программа начинается при более низких температурах и имеет другой температурный режим, то позволяет дифференцировать легкие УВ, тяжелые УВ и смолы, а также асфальтены и тяжелую часть смол. Параметр Ттахb показывает преобразованность битума, при котором сложные молекулы асфальтенов претерпевают крекинг, а простые молекулы соответственно, увеличивают пик $\mathrm{S}_{1}$. Таким образом, битум формируется за счет термического испарения в инертной атмосфере. По сравнению с методом анализа экстрактов метод пиролиза для определения битума имеет преимущество в повышенной скорости и возможности анализа УВ ниже $\mathrm{C}_{15}$, обычно нечетко определяемые в связи с их удалением при испарении растворителя [2]. Усредненные параметры проб асфальтита по программе reservoir приведены в Таблице 1.

Таблица 1 Параметры образцов по программе reservoir. Reservoir parameters

\begin{tabular}{|c|c|c|c|c|c|c|c|}
\hline \multicolumn{7}{|c|}{ Reservoir parameters } \\
\hline $\mathrm{S}_{1} \mathrm{r}$ & $\mathrm{S}_{2} \mathrm{a}$ & $\mathrm{S}_{2} \mathrm{~B}$ & OIL & Tmaxb & $\mathrm{S}_{1 \mathrm{r}}(\%)$ & $\mathrm{RCr}(\%)$ & NSOKERO \\
\hline 12,06 & 27,26 & 388,32 & 39,32 & 435 & 1,66 & 27,39 & 94,63 \\
\hline
\end{tabular}


Количество (Q) гетероатомных соединений нефтяного ряда (в мг/г породы) равно:

$\mathrm{Q}=\mathrm{S}_{2} \mathrm{~b}+10 \mathrm{RC} / 0,9=388,3+10 \cdot 27,39 / 0,9=692,6 \mathrm{м \Gamma} / \mathrm{r}$.

где Q - количество гетероатомных соединений NSO (кислые смолы и асфальтены), мг УВ/г породы; 0,9 - средняя пропорция органического углерода в коксе; RC - остаточный углерод, \%. Низкое значение индекса продуктивности:PIr $=\left(\mathrm{S}_{1} \mathrm{r}+\mathrm{S}_{2} \mathrm{a}\right) /\left(\mathrm{S}_{1} \mathrm{r}+\mathrm{S}_{2} \mathrm{a}+\mathrm{S}_{2} \mathrm{~b}\right)=(12,06+27,26) /(12,06$ $+27,26+388,3)=0,09$, (менее 0,4$)$ указывает на наличие NSO (асфальто-смолистые вещества, пик $\mathrm{S}_{2} \mathrm{~b}$ ). Параметр ТОC = 62,91 \% показывает содержание органического углерода в битуме, a 37,09 \% приходится на $\mathrm{H}, \mathrm{O}, \mathrm{N}, \mathrm{S}$, и минеральную составляющую - золу. Содержание асфальто-смолистых веществ составляет $\sim 95 \%$. ИК-спектры в диапазоне $4000-650 \mathrm{~cm}^{-1}$ были получены на приборе Agilent Cary 600 на приставке НПВО с кристаллом из селенида цинка. Разрешение составляло $4 \mathrm{~cm}^{-1}$, количество сканов - 32. ИК -спектры асфальтита содержат интенсивные полосы $2920 \mathrm{~cm}^{-1}$ и $2850 \mathrm{~cm}^{-1}$ валентных и $1240 \mathrm{~cm}^{-1}$ и деформационных колебаний связей $\mathrm{C}-\mathrm{H}$; сильная полоса $1460 \mathrm{~cm}^{-1}$ отвечает колебаниям ароматического кольца, которым также соответствуют слабые полосы в области $1600 \mathrm{~cm}^{-1}$. Слабые полосы в области $720 \mathrm{~cm}^{-1}$ $865 \mathrm{~cm}^{-1}$ соответствуют деформационным колебаниям $\mathrm{C}-\mathrm{H}$ связей ароматических колец. Присутствие карбонильных соединений (в том числе и амидов) в составе асфальтита регистрируется интенсивной полосой в области $1740 \mathrm{~cm}^{-1}$. Изотопный анализ углерода асфальтита выполнялся на изотопном масс-спектрометре VG OPTIMA фирмы Fisons. В качестве стандартных образцов использовали международный газовый стандарт двуокиси углерода TEX-843C и международный стандарт образец масла LAEA NBS22. Результаты выражены в виде значений $\delta^{13} \mathrm{C}(\%)$, представляющие собой отклонение изотопного состава образца от изотопного состава международного стандарта VPDB: $\delta^{13} \mathrm{C}=\left[\left({ }^{13} \mathrm{C}{ }^{2} \mathrm{C}\right)\right.$ обр/ $\left.\left({ }^{13} \mathrm{C}^{42} \mathrm{C}\right) \mathrm{VPDB}-1\right] * 103(\%)$, где $\left({ }^{13} \mathrm{C} /{ }^{12} \mathrm{C}\right) \mathrm{VPDB}=0.0112372$.

Точность измерений $\pm 0,5 \%$. Значения $\delta^{13} \mathrm{C}$ приведены относительно VPDB. Воспроизводимость результатов анализа $\pm 0.3 \%$. Пять образцов асфальтита показали аналогичную сигнатуру $\delta^{13} \mathrm{C}(-30,81 \%)$ и таким образом оказались полностью однородными, указывающими на их органическое происхождение.

По результатам биомаркерных исследований [3-7] выявлены генетические параметры асфальтита- пристан/фитан, пристан/н-С17Н36 и фитан/н-С18Н38 характеризуют асфальтит как флюид морского генезиса. Отношение стеранов $\mathrm{C}_{28} / \mathrm{C}_{29}, 0.31$, по Грандхему соответствует силуру, а по прегнановому коэффициенту - отношению суммы прегнанов $\mathrm{C}_{21}-\mathrm{C}_{22}$ к сумме прегнанов $\mathrm{C}_{21}-\mathrm{C}_{22}$ и регулярных стеранов $\mathrm{C}_{27}-\mathrm{C}_{29}$, равному $9.0 \%,-$ возрасту старше силура. Коэффициентам зрелости К1зр и К2зр (0.53 и 0.79$)$, находятся почти на уровне равновесных значений, что позволяет судить о зрелости асфальтит. Отношения диа/рег стеранов 0.04 индикатор осадконакопления в карбонатных толщах. Таким образом, асфальтит находится во вторичном залегании. Можно предположить, что осадконакопление происходило в карбонатных толщах в восстановительных условиях. Большая величина отношения $\Gamma_{30} / \mathrm{C}_{29}-$ показатель развитых бактериальных процессов.

Физико-химические свойства асфальтита месторождения Ивановское: температура размягчения $\sim 200{ }^{\circ} \mathrm{C}$, зольность $-4,0 \%$, влажность $-1,0 \%$. Групповой состав: асфальтены $68 \%$, смолы - $20 \%$, масла $-12 \%$, кислотное число - 14,0 мг КОН/г.

По результатам элементного анализа получены концентрации элементов: С - 81,2\%, $\mathrm{H}-1,2 \%$, $\mathrm{O}-0,7 \%, \mathrm{~S}-2,5 \%$. Cl -0,25\%, Si - 0,25\%, V-0,20\%, Ni -0,03\%, Ca - 0,17\%, Fe-0,002\%, Mo$0,002 \%$. Асфальтит не растворим в обычных растворителях, кроме хлороформа, сероуглерода и комплексного растворителя, состоящего из этанола, $\mathrm{C}_{2}-\mathrm{C}_{4}-$ хлорпроизводных и $3,4-$ дихлор, тиофен - 1,1-диоксида, а также в дейтеробензоле. ПМР - спектр растворенной фазы асфальтита в дейтеробензоле, измеренный на ЯMP - спектрометре BRUKER MSL-300, показал низкое содержание алкильных, алкенильных и бензильных протонов (сигналы до 4 м.д.) и повышенное содержание арильных протонов (сигналы 6,5-8 м.д.), что позволяет предположить высоко конденсированные ароматические системы с алкильными и алкенильными заместителями. 
Повышенная концентрация металлов в тяжелых нефтяных остатках объясняется присутствием в них асфальто-смолистых соединений [8-13]. Расчеты результатов анализа, проведенные относительно матрицы обедненной водородом, показали повышенное содержание ванадия 2000 г/т., а никеля на порядок меньше 300 г/т. Как правило, количество порфиринов никеля и ванадия в нефти симбатно содержанию в ней серы, причем в сернистых нефтях порфирины металлов почти нацело представлены ванадил-порфиринами, а в малосернистых комплексами с никелем. При повышенном содержании асфальто-смолистых веществ и сернистых соединений преобладают концентрации ванадий органических соединений по сравнению с соединениями никеля, что подтверждается результатами элементного анализа.

Таким образом, асфальтиты месторождения Ивановское представляют коммерческий интерес в качестве объекта извлечения из них стратегических металлов.

\section{Выводы}

На основании полученных результатов выявлено, что исходным материалом для формирования асфальтита Ивановского месторождения являлась нефть, генерированная на стадиях катагенеза, соответствующих началу главной фазы нефтеобразования. Седиментация и диагенез проходили в прибрежно-морских условиях в восстановительной обстановке в зоне сероводородного заражения.

\section{Библиография / References}

1. O.YU. Batalin, N.G. Vafina Formy zahvata svobodnyh uglevodorodov kerogenom // Mezhdunarodnyj zhurnal prikladnyh i fundamental'nyh issledovanij. 2013. №10.S.418-425.

2. EHspital'e Dzh., Droued S., Markuis F. Ocenka neftenosnosti s pomoshch'yu pribora Rock-Eval s komp'yuterom/ Geologiya nefti i gaza. -1994.- №1.- s.23-32.

3. V.Yu. Kerimov, A.L. Lapidus, N.Sh. Yandarbiev, E.M. Movsumzade, R.N. Mustaev Physicochemical properties of shale strata in the Maikop series of Ciscaucasia // Solid Fuel Chemistry, 2017, 51(2), 122-130

4. Kerimov V.Yu., Serikova U.S., Mustayev R.N., Guliyev I.S. Deep oil-and-gas content of South Caspian Basin // Neftyanoe khozyaystvo - Oil Industry. - Moscow, 2014. - №5. - PP. 39-42

5. Kerimov V.Yu., Mustaev R.N., Serikova U.S., Lavrenova E.A., Kruglyakova M.V. Hydrocarbon generation-accumulative system on the territory of Crimea Peninsula and adjacent Azov and Black Seas // Neftyanoe Khozyaystvo - Oil Industry. - Moscow, 2015. - №3. - pp. 56-60

6. Kerimov V.Yu., Mustaev R.N., Dmitrievsky S.S., Yandarbiev N.Sh., Kozlova E.V. The shale hydrocarbons prospects in the low permeability khadum formation of the Pre-Caucasus // Neftyanoe Khozyaystvo - Oil Industry. - Moscow, 2015. - №10. - PP. 50-53.

7. Kerimov V.Y., Gorbunov A.A., Lavrenova E.A., Osipov A.V. Models of hydrocarbon systems in the Russian Platform-Ural junction zone // Lithology and Mineral Resources. - Moscow, 2015. - V. 50, №5. - PP. 394-406.

8. Guliev I.S., Kerimov V.Yu., Mustaev R.N. Fundamental challenges of the location of oil and gas in the South Caspian Basin // Doklady Earth Sciences. - Moscow, 2016. - V. 471, №1. - PP. 11091112.

9. Kerimov V.Yu., Shilov G.Ya., Mustayev R.N., Dmitrievskiy S.S. Thermobaric conditions of hydrocarbons accumulations formation in the low-permeability oil reservoirs of khadum suite of the Pre-Caucasus // Neftyanoe Khozyaystvo - Oil Industry. - Moscow, 2016. - №2. - PP. 8-11.

10.Kerimov V.Yu., Osipov A.V., Lavrenova E.A. The hydrocarbon potential of deep horizons in the south-eastern part of the Volga-Urals oil and gas province // Neftyanoe khozyaystvo - Oil Industry. Moscow, 2014. - №4. - PP. 33-35.

11.Kerimov V.Y., Rachinsky M.Z. Geofluid dynamic concept of hydrocarbon accumulation in natural reservoirs // Doklady Earth Sciences. - Moscow, 2016. - Vol. 471, №1 . - PP. 1123-1125.

12.Kerimov V.Yu., Mustaev R.N., Bondarev A.V. Evaluation of the organic carbon content in the low-permeability shale formations (as in the case of the Khadum suite in the Ciscaucasia region // Oriental Journal of Chemistry. - India, 2016. - Vol. 32, №6. - PP. 1-7. 


\section{EAGE}

13.Kerimov, V.Yu., Mustaev, R.N., Serikova, U.S., Lavrenova, E.A., Kruglyakova, M.V. Hydrocarbon generation-accumulative system on the territory of Crimea Peninsula and adjacent Azov and Black Seas Neftyanoe khozyaystvo - Oil Industry. - Moscow, 2015. - №2.

14. R.N. Mustaev Geochemical Environment of Oil and Gas Occurrences in the South-Caspian Basin Based on the Results of the Study of Mud Volcano Ejecta // Oriental Journal of Chemistry. 2017. V.33. №4. 